\title{
Review and Outlook of Stem Cell Transplantation for Neonatal Hypoxic- Ischemic Encephalopathy
}

\author{
Qiu-li WANG ${ }^{1}$, Hong-yan LV ${ }^{1,2}$, Peng-shun REN ${ }^{1}$ \\ and Lian-xiang $\mathrm{LI}^{2,3, \mathrm{a},{ }^{*}}$ \\ 1Department of Neonatology, Handan Maternal and Child Health Care Hospital, \\ Handan 056001, Hebei Province, PR China \\ ${ }^{2}$ Department of Neonatal Pathology, Handan Maternal and Child Health Care Hospital, \\ Handan 056001, Hebei Province, PR China \\ ${ }^{3}$ Department of Neural Development and Neural Pathology, Hebei University of \\ Engineering School of Medicine, Handan 056029, Hebei Province, PR China \\ alianxianglm68@163.com \\ *Corresponding author
}

Keywords: Neonate, Hypoxic ischemic encephalopathy, Stem cell transplantation, Nerve regeneration, Nerve repair, Tissue engineering.

\begin{abstract}
Purpose: To research the states and feasibility of stem cells for neonatal hypoxic ischemic encephalopathy (HIE). Methods: In this study, "newborn, hypoxic ischemic encephalopathy, pathogenesis, stem cell transplantation" as the key words, which are searched the papers published in CNKI database and PubMed from January 1984 to December 2016.The efficacy of stem cell for neonatal HIE in animal and clinical trials are reviewed. Results: There are three types of stem cells for neonatal HIE including neural stem cells, mesenchymal stem cells and umbilical cord blood mononuclear stem cells. The methods and delivery routes of stem cell transplantation include intracerebra, intrathecal, peripheral intravascular and intranasal delivery. A large number of animal experiments have shown that stem cell for neonatal HIE may promote the differentiation and proliferation of endogenous stem cells, reduce the apoptosis of damaged brain tissue and improve the neurobehavioral function of animals. Clinical trials have shown that stem cell for neurological deficits in neonates with HIE has been significantly improved. Conclusions: Stem cell transplantation for neonatal HIE is a promising method, but some problems need to be solved urgently.
\end{abstract}

\section{Introduction}

Neonatal hypoxic ischemic encephalopathy (HIE) is a brain lesion caused by perinatal hypoxia, which is one of the main causes of neonatal death and disability. According to reports in the literature, Neonatal HIE occurs in 0.37 to 8 per 1000 live births in developed countries $[1,2,3,4,5]$, among of neonates with HIE are about $15-20 \%$ of the patients died in the neonatal period and left permanent cerebral palsy, mental retardation, epilepsy and other neurological disorders in 25-30\% survivors $[6,7,8,9]$ which is bring great spiritual and economic burden to society and family, and serious damage to the children's quality of life. Mild hypothermia is a safe, effective and feasible method for the treatment of neonatal HIE, nevertheless, in mild hypothermia therapy in patients with neonatal HIE, there are still occurred in 44-53\% died or left a moderate and severe neurological dysfunction [10, 11]. In the acute stage, the use of supportive therapy and rehabilitation training in the later stage has a certain effect on the recovery of part of brain function in patients, but it can not 
prevent the occurrence of neurological sequelae. In recent years, stem cells are transplanted into the brain tissue of neonatal HIE, Stem cells may not only survive, but also may be differentiated into neurons and glial cells, reconstruction of neural pathways, improve brain damage caused by dysfunction[12], it brings new hope for the patient of neonatal HIE.

\section{Stem Cell Source and Classification}

Stem cells are an undifferentiated and immature cells with the potential to self renew, highly proliferating and multilineage differentiation which are the origin of tissue and organ, and are the core component of regenerative medicine.

There are two methods to classify stem cells: (1) According to the developmental stage of stem cells, they can be divided into embryonic stem cells (ESC) and somatic stem cells(SSC). ESC is derived from embryos, are highly undifferentiated cells with the ability to differentiate all the tissues and organs of animals, because of ethical issues, the application of the controversial. SSC is derived from many tissues and organs of adult animals, which can produce new stem cells, but the dynamic balance of growth and decline of tissues and organs. The potential of SSC is relatively weak, and does not involve ethical issues, SSC are rich in source, including neural stem cells (NSC), hematopoietic stem cell (HSC), bone marrow-derived mesenchymal stem cells ( BM-MSC), epidexmis stem cell and so on. SSC may be obtained from the following as: A. Embryonic cells - directed differentiation of embryonic stem cells or transplantation differentiation. B. Embryo tissue- formed by the isolated embryonic tissue, solated cell or cell cultures. C. somatic tissues obtained from cord blood, placenta, bone marrow, peripheral blood and adipose cells. (2) According to the developmental potential of stem cells, which may divided into totipotent stem cell (TSC), pluripotent stem cells (PSC) and unipotent stem cell (USC). TSC have the potential to form a complete individual, such as embryonic stem cells, it has a strong ability to differentiate with a similar morphological characteristics of early embryonic cells; PSC have the potential to differentiate into multiple tissue cells, such as embryonic stem cells; USC may differentiate into one type or two closely related cell types, such as neural stem cells, hematopoietic stem cells.

A large number of animal experiments or clinical trials have been shown that stem cells with paracrine factors not only may effectively repair the damaged tissues and organ of body, but also it has inestimable value in clinical medicine and market prospect. Stem cells provide a new method for the treatment of cardiovascular diseases, metabolic diseases, nervous system diseases, blood system diseases, autoimmune diseases and other important diseases.

\section{Methods and Delivery Routes of Stem Cell Transplantation}

There are many methods for stem cell transplantation, such as intracerebral delivery, intrathecal delivery, peripheral intravascular delivery, intranasal delivery and intraperitoneal delivery and so on.

\section{Intracerebral Delivery}

The stem cells are injected directly into the brain tissue [13,14 ]. The method is followed by stereotactic localization, local anesthesia, skull drilling, insertion of probes and stem cells are injected by micro pump into brain tissue. The advantage of this method is that stem cells may be concentrated to the focus with surrounding, the immune reject of peripheral lymphocytes and blood cerebrospinal fluid barrier are avoided, thereby reducing the loss of stem cells during transplantation and improving 
the transplant efficiency. But the disadvantage of this method is that the stem cells are injected directly into the brain to penetrate the skull and brain tissue, causing mild brain injury and the high risk, high request, inconvenience many times, multi-target injection, intracranial hypertension and so on. Intracerebral delivery is applied for clinical, the families of patients with a variety of concerns, it is difficult to accept, the opportunities of treatment often give up.

\section{Intrathecal Delivery}

It is called subarachnoid injection, because animal experiments are mostly rats, lumbar puncture is difficult to achieve, therefore, the lateral intraventricular injection is instead of lumbar puncture injection [15]. The advantage of this method is that the transplanted stem cells are injected directly into the subarachnoid space, and the injury degree is smaller than that intracerebral delivery, clinically, injection of stem cells by lumbar puncture in children, the families of patients is easy to accept, however, the lateral intraventricular delivery may cause mild secondary brain injury, the families of patients is not easy to be accepted. The disadvantage of this method is that stem cells need to pass the blood-cerebrospinal fluid barrier into brain tissue, at present, there is still little research on stem cells in this delivery route, and its effect is to be evaluated.

\section{Peripheral Intravascular Delivery}

Animal experiments are performed by internal carotid artery [16] or rat tail vein injection [17]. The method is that stem cells are injected into the arteries or veins, stem cells reach the damaged brain tissue through blood circulation. The advantage of this method is that the operation is simple, the stem cells are widely distributed, and less interference to nerve tissue, injections may be repeated. The disadvantage is that the migration of stem cells pass the blood-brain barrier, the passage rate of stem cells is reduced. When stem cells through the lungs or brain, it may lead to pulmonary or cerebral thrombosis.

\section{Intranasally Delivery}

The stem cells are injected into the nasal mucosa, and the stem cells migrated to the injured brain tissue via endocytosis of the olfactory neurons or trigeminal ganglion cells [18]. The advantage is that the stem cells may reach the damaged brain tissue at a short distance route, less loss of stem cells, injections can be repeated, and the stem cells can avoid the influence of the blood-brain barrier to reach the damaged brain region. The intranasally delivery is safe, simple, easy to accept and is a promising delivery route to transplant

\section{Current Status of Stem Cells for Neonatal HIE}

For a long time, it has been believed that brain cells may not regenerate after injury. However, animal experiments have been shown that stem cells may effectively promote the recovery of neurological function in neonatal HIE animal model, therefore, the research on exogenous stem cell transplantation for neonatal HIE has aroused the interest of many scholars. Up till now, stem cell transplantation is more common in animal experiments, there are only a few reports of clinical trials. Nevertheless, it opens up a new way to treat HIE in neonates [19]. At present, the stem cell types used for neonatal HIE are mainly focused on neural stem cells, mesenchymal stem cells and human umbilical cord blood mononuclear cells. 


\section{Neural Stem Cells( NSCs)}

NSCs have the ability to self renew and differentiate into neurons and glial cells as well as the ability to migrate and settle in the damaged areas of the central nervous system. The study found that NSCs widely exists in the embryonic and adult nervous system, and may be differentiated into neurons, astrocytes and oligodendrocytes in vivo or in vitro, it has shown to repair for the brain injury. However, the ability of neural cells to repair themselves is limited [20]. Therefore, it is possible to repair damaged brain tissue with exogenous stem cells.

Animal experiments show that the human embryonic NSCs are transplanted into the ventricle of HIE neonatal rats, stem cells can reach to the area of brain damage along the sub-ventricle zone (SVZ) and corpus callosum, especially in the cerebral cortex and hippocampus, $85 \%$ transplanted cells form hNuc-NF or hNuc-Tublin positive cells in the cerebral cortex, $60 \%$ transplanted cells differentiate into hNuc-GFAP positive cells [21]. At the same time, stem cells have the function of enhancing endogenous brain repair [22], stem cells have strong ability of regeneration and differentiation, if the embryonic stem cell derived neural precursor cells (NPCs) are transplanted into the deep cerebral motor cortex of neonatal HIE rats, 3 weeks after implantation, NPCs can be differentiated into neurons in the cortex, the motor function of rats are improved [23]. pluripotent stem cells of mouse are transplantated into rat brain,it can be differentiated into neurons and astrocytes [24]. In addition, the survival, proliferation and differentiation of stem cells depend on the support of neurotrophic factors brain derived neurotrophic factor (BDNF) can promote the growth of transplanted stem cells in the injured brain area, and promote the recovery of neural function[25]. In order to reduce the damage of stem cells into the brain during the process of transplantation, human embryonic neural stem cells (hNSCs)are transplantated into the nasal cavity of HIE newborn rats, the results show that hNSCs are widely distributed in different regions of brain, the expression of cytokine LI-1 $\beta$, P-Lk $\beta a, N F-k \beta$ and p65 are decreased, the neurological function are improved[26], intranasally delivery is a non-invasive transplantation method which provides a simple and convenient method for stem cell for neonatal HIE in the future.

In recent years, human fetal neural stem cells (hNSCs ) transplantation for neonatal HIE has made great progress in the clinical application, Luan $\mathrm{Z}$ et al. study that hNSCs are transplanted into one case of neurological disability infant who is caused severe HIE after birth 75 days of ages, twenty eight days after hNSCs transplantation, remarkable improvement occurred not only in his myotonia but also in his intelligence and movement, which became similar to those of the normal infants of the same age [27 ]. Later, they implanted with human neural progenitor cells for 6 cases of neonatal HIE brain damage, second days after transplantation, all patient's sucking and swallowing reflex appear, twitch stop, muscle tone are improved, at the same time, all patients are followed up for 12 months, of 4 cases of infant who mental motor development and the scale scores reache normal level, 2 cases of cerebral appear palsy [28]. The results of clinical trials show that NPCs transplantation is safe and effective for severe neonatal brain injury, and has accumulated valuable experience for further research and application.

\section{Mesenchymal stem cells (MSCs)}

MSCs are a kind of somatic stem cells with self-renewal and multilineage differentiation potential, which are found in bone marrow, cord blood, adipose tissue and fetal tissues. 


\section{Bone Marrow-Derived Mesenchymal Stem Cells (BM-MSCs)}

BM-MSCs may stimulate the repair process by secreting growth factors and improve neonatal hypoxic ischemic brain damage. Animal experiments have show that human or rat BM-MSCs may improve the motor function, learning and memory function, when BM-MSCs is transplantated into the brains of neonatal HIE rats[29,30]. It is also found that the glial fibrillary acidic protein and OX42 are more abundant in region of stem cells [31], and it may promote the differentiation and regeneration of new cells toward neurons and oligodendrocytes [32]. In addition, the transplanted BM-MSCs can also promote the up regulation of endogenous repair factors and improve the sensorimotor function [33]. Animal experiments show that the timing of stem cell transplantation has a close relationship with the treatment results. Donega $\mathrm{V}$, et al. studied that PKH-26 labeled cells as BM-MSC in the localization of the brain, the content of BM-MSC $\left(0.5 \times 10^{(6)}\right)$ are used as the minimum effective dose, the stem cells are transplanted in the nasal cavity of 9 days old mice with HIE. BM-MSC are transplanted into mice at $3 \mathrm{~d}$ or $10 \mathrm{~d}$ after HIE, The results show that the stem cells can reach the diseased area within 24 hours, which may improve the cognitive function and the sensory motor function; when BM-MSC are implanted into mice at $17 \mathrm{~d}$ after HIE, BM-MSC are not detected in the lesion[ 34]. Further studies have shown that BM-MSC are transplanted by intranasal which may decrease the activity of astrocytes and microglia in the brain tissue of neonatal rats with HIE, and promote neuronal regeneration, reduce scar formation [35]. Effects of different neurotrophic factors or growth factors on BM-MSC in the differentiation and proliferation are significant differences. In vitro, the brain-derived neurotrophic factor(BDNF), epidermal growth factor 7(EGFL7), persephin (PSP) or sonic hedgehog(Shh)secreted by MSC,which can regulate the proliferation and differentiation of neural stem cells. Interestingly, different gene modified stem cells have different effects on brain damage in neonatal HIE mice, MSCs-BDNF implanted in HIE mice may significantly improve motor function and reduce brain lesion size; MSCs-EGFL7 may only improve motor function, but has effect on lesion size; MSCs-Shh or MSCs-PSP neither improved outcome nor reduced lesion size [36]. It is of great significance to guide the selection of different neurotrophic factors or growth factors in stem cell transplantation. In order to enhance the effect of stem cell transplantation, neurotrophic factor or growth factor is also the focus of future research.

\section{Umbilical Cord Blood -Derived Mesenchymal Stem Cells (UCB-MSCs)}

UCB-MSCs are a more primitive MSC group with the following advantages: (1) a wide range of sources, easy to collect, easy to expand, no ethical issues; (2) the proliferation ability of UCB-MSCs are several times faster than BM-MSCs.

Some scholars study that human umbilical cord blood mesenchymal stem cells are transplanted into HIE rats from intravenous delivery, which may promote the recovery of rat's behavior and reduce the proliferation of glial cells in cerebral ischemic area, if ganglioside treatment is given at the same time, which may further enhance the recovery of nerve function [37]. In addition, there are reports that human UC-MSCs is transplanted into neonatal HIE rats, it may reduce the damage of brain tissue apoptosis early after implantation, decreased the expression of Caspase-3; Late after transplantation, human UC-MSCs may differentiate into neurons and promote the differentiation of endogenous neural cells [38].In contrast, it has been reported that the transplanted human UCB-MSCs can only differentiate into microglia and astrocyte [39], and cannot differentiate into neurons [40]. Therefore, what type of nerve cells are differentiated after stem cell transplantation? It is necessary to clarify. 


\section{Dental Pulp Stem Cells-Derived Stem Cells (DPSCs)}

DPSCs have the characteristics of NSCs and MSCs [41]. Recently, some scholars study that human DPSCs are transplanted into neonatal HIE animal model, the result show that human DPSCs may reduce the brain injury of mice HIE, inhibition of proinflammatory cytokines and cell apoptosis[42]; Also find that DPSCs may an directly differentiate into neurons or glial cells, promote the proliferation of host stem cell and differentiation into neurons or glial cells, meanwhile, human DPSCs also may improve the neural behavior of animal[43]. DPSCs as a new member of stem cells, it will play an key role for nerve injury disease.

\section{Human Umbilical Cord Blood Mononuclear Cells ( HUCB-MCs)}

UCB-MCs is rich in immature stem cells which is an important target for refractory central nervous system (CNS) diseases. Cord blood transplantation has a strong potential for nerve regeneration. The mechanism of UCB-MCs for neonatal HIE may be related to neuroprotection, anti-inflammation, angiogenesis, neurogenesis and stimulate the release of endogenous neurotrophic factors. It has been demonstrated that human UCB-MCs are effective for central nervous system (CNS) injury. UCB-MCs are easier to obtain than other stem cells and safer transplantation [44]. Therefore, umbilical cord blood cell transplantation for neonatal HIE has great potential and prospects. Animal experiments showed that transplantated human UCB-MCs into neonatal HIE rats may decrease the activity of microglia, inhibit the death of neurons and promote the recovery of sensory motor reflex [45], promote endogenous neural stem cells to differentiate into mature nerve cells [46], promote the recovery and development of damaged brain cells [47], reduce neurological deficit [48], UCB-MCs transplantion for neonatal HIE rats may improved learning and long-term spatial memory [49,50].

In order to promote the passage of UCB-MCs through the blood-brain barrier, the human UCB-MCs are added into mannitol from intravein delivery, it is found that the transplanted UCB-MCs may promote the up regulation of brain-derived neurotrophic factor [51]. Therefore, the human umbilical cord blood stem cells for reduction of neurological deficit caused by neonatal HIE has great potential [52], which is the best intervention measures and a wide application prospect.

\section{Conclusions}

Animal experiments and clinical trials have shown that stem cell transplantation for neonatal HIE is significant, In particular, human umbilical cord blood mononuclear cells is early intervention for neonatal HIE by intranasal delivery, it is a promising treatment method. However, there are still many problems to be solved in the treatment of neonatal HIE, For example: the best choice for stem cell types, the best delivery route of stem cells, the best time for stem cell transplantation, the reconstruction of the morphological structure of neurons or glial cells after stem cell transplantation, regulation of stem cell migration, proliferation and differentiation in vitro as well as the efficacy evaluation of long term and so on. We believe that these problems are solved, stem cells for neonatal HIE in clinical will be widely carried out. 


\section{Reference}

[1] García-Alix A,Martínez-Biarge M, Diez J, Gayá F, Quero J. Neonatal hypoxic-ischemic encephalopathy:incidence and prevalence in the first decade of the 21st century.An pediatr(Bare). 71(2009)319-326

[2] Hull J, Doddk L. Falling incidence of hypoxic-ischaemic encephalopathy interm infants. Br J Obstet Gynaecol. 99(1992)386-391

[3 ] Hayakawa M. Ito Y, Saito S, Mitsuda N, Hosono S, Yoda H, Cho K, Otsuki K, Ibara S, Terui K, Masumoto K, Murakoshi T, Nakai A, Tanaka M, Nakamura T: Executive Committee, Symposium on Japan Society of perinatal and Neonatal Medicine. Incidence and prediction of outcome in hypoxic-ischemic encephalopathy in Japan. Pediatr Int. 56(2014)215-221

[4] Douglas-Escobar M, Weiss MD. Hypoxic-ischemic encephalopathy: a review for the clinician. JAMA Pediatr. 169(2015)397-403

[5] Boo NY, Cheah IG. The burden of hypoxic-ischaemic encephalopathy in Malaysian neonatal intensive care units. Singapore Med J.57 (2016)456-463

[6] Nelson KB, Ellenberg JH. Obstetric complication as risk factors for cerebral palsy or seizure disorders. JAMA. 251(1984)1843-1848

[7] Gieron-Korthals M, Colón JH. Hypoxic-ischemic encephalophathy in infant: New challenges. Fetal pediatr Pathol. 24 (2005)105-120

[8] Nikas I, Dermenttzoglou V, Theofanopoulou M, Theodoropoulos V. Parasagittal lesions and ulegyria in hypoxic-ischemic encephalopathy: neuroimaging findings and review of the pathogenesis. J Child Neurol. 23(2008)51-58

[9] Lai MC, Yang SN. Perinatal hypoxic-ischemic encephalopathy. J Biomed Biotechnol. 2011(2011)609813

[10] Edwards AD, Brocklehurst P, Gunn AJ, Halliday H, Juszczak E, Levene M, Strohm B, Thoresen M, Whitelaw A, Azzopardi D. Neurological outcomes at 18 months of age after moderate hypothermia for perinatal hypoxic ischaemic encephalopathy:synthesis and meta-analysis of trial data. BMJ.340 (2010) c363

[11] Wu YW, Gonzalez FF. Erythropoietin: a novel therapy for hypoxic-ischaemic encephalopathy? Dev Med Child Neurol. 3(2015)34-39

[12] Jansen EM, Solberg L, Underhil S, Wilson S, Cozzari C, Hartman BK, Faris PL, Low WC. Transplantion of fetal neocortex ameliorates sensorimotor and locomotor deficits following neonatal ischemic-hypoxic brain injury in rats. Exp Neurol. 147(1997)487-497

[13] Sato Y, Nakanishi K, Hayakawa M, Kakizawa H, Saito A, Kuroda Y, Ida M, Tokita Y, Aono S, Matsui F, Kojima S, Oohira A. Reduction of brain injury in neonatal hypoxic-ischemic rats by intracerebroventricular injection of neural stem/progenitor cells together with chondroitinase ABC. Reprod Sci. 15(2008)613-620

[14] Obenaus A, Dilmac N, Tone B, Tian HR, Hartman R, Digicaylioglu M, Snyder EY, Ashwal S. Long-term magnetic resonance imaging of stem cells in neonatal ischemic injury, Ann Neurol. 69(2011) 282-291 
[15] Yan SZ, Wang XL,Wang HY, Dong P, Zhao YS. Effects of umbilical cord blood mononuclear cells transplantation via lateral ventricle on the neural apopotosis and the expression of Bax and Bcl-2 proteins in neonatal rats with hypoxic-ischemic brain damage. Zhongguo Dang Dai Er Ke Za Zhi. 18 (2016) 862-866 [ in Chinese ]

[16] Janowski M, Lyczek A, Engels C, Xu J, Lukomska B, Bulte JW, Waiczak P. Cell zise and velocity of injection are major determinants of the safety of intracarotid stem cell transplantation. J Cereb Blood Flow Metab. 33(2016)921-927

[17] Yansuhara T, Hara K, Maki M, Mays RW, Deans RJ, Hess DC, Carroll JE, Borlongan $\mathrm{CV}$. Intravenous grafts recapitulate the neurorestoration afforded by intracerebrally delivered multipotent adult progenitor cell in neonatal hypoxic-ischemic rats. J Cereb Blood Flow Metab, 28(2008)1804-1810

[18] Lochhead JJ, Thorne RG. Intranasel delivery of biologics to the central nervous system. Adv Drug Deliv Rev. 64(2012) 614-628

[19]Chicha L, Smith T, Guzman R.Stem cells for brain repair in neonatal hypoxia-ischemia.Childs Nerv Syst. 30(2014) 37-46

[20] Ikeda T, Iwai M, Hayashi T, Naganol I, Shogi M, Ikenoue T, Abe K. Limited differentiation to neurons and astroglia from neural stem cell in the cortex and striatum after ischemia/ hypoxia in the neonatal rat brain. Am J Obstet Gynecol. 193(2005)849-856

[21] Qu SQ, Luan Z, Yin GC, Guo WL, Hu XH, Wu NH, Yan FQ, Qian YM. Transplantation of human fetal neural stem cells into cerebral ventricle of the neonatal rat following hypoxic-ischemic injury: survival, migration and differentiation. Zhonghua Er Ke Za Zhi. 43(2005)576-579 [ in Chinese ]

[22] Daadi MM, Davis AS, Arac A, Li Z, Maag AL, Bhatnagar R, Jiang K, Sun G, Wu JC, Steinberg GK. Human neural stem cell grafts modify microglial response and enhance axonal sprouting in neonatal hypoxic-ischemic brain injury. Stroke. 41(2010)516-523

[23] Shinoyama M, Ideguchi M, Kida H, Kajiwara K, Kagawa Y, Maeda Y, Nomura S, Suzuki M. Cortical region-specific engrafment of embryonic stem cell-derived neural progenitor cell restores axonal sprouting to a subcortical target and achieves motor functional recovery in a mouse model of neonatal hypoxic-ischemic brain injury. Front Cell Neurosc. 7(201)128

[24] Zheng T, Rossignol C, Leibovici A, Anderson KJ, Steindler DA, Weiss MD. Transplantation of multipotent astrocytic stem cells into a rat model of neonatal hypoxic-ischemic encephalopathy. Brain Res. 1112(2006)99-105

[25] Wang HY, Zhu XF, Wang LM, Luo ZH, Yang ZJ, Liu D, Yuan DX, Nie L, Wu $\mathrm{YJ}<$ Wang SX. Brainiderived neurotrophic factor and neural stem cells transplantation in treatment of hypoxic-ischemic brain injury in rats. Zhonghua Er Ke Za Zhi.46 (2008)544-549 [in Chinese ]

[26] Ji G, Liu M, Zhao XF, Liu XY, Guo QL, Guan ZF, Zhou HG, Guo JC. NF-kB signaling is involved in the effects of intranasally engrafted human neural stem cells on neurofunctional improvements in neonatal rat hypoxic-ischemic encephalopathy.CNS Neurosci Ther. 21(2015)926-935 
[27] Luan Z, Yin GC, Hu XH, Qu SQ, Wu NH, Yan FG, Qian YM, Jin HY, Gong XJ. Treatment of an infant with severe neonatal hypoxic-ischemic encephalopathy sequelae with transplantation of human neural stem cell into cerebral ventricle. Zhonghua Er Ke Za Zhi. 43(2005)580-583 [in Chinese ]

[28] Luan Z, Liu EP, Qu SQ, Hu XH, Wang ZY, He S, Liu CQ, Xiao M. Treatment of newborns with severe injured brain with transplantation of human neural precursor cell. Zhonghua Er Ke Za Zhi. 49(2011)445-449

[29] Yasuhara T, Matsukawa N, Yu G, Xu L, Mays RW, Kovach J, Deans RJ, Hess DC, Carroll JE, Borlongan CV. Behavioral and histological characterization of intrahippocampal grafts of human bone marrow-derived multipotent progenitor cells in neonatal rats with hypoxic-ischemic injury. Cell Transplant. 15(2006)231-238

[30] Liu Y, Zhang X, Dai Y, Shu C, Qu P, Liu YX, Yang L, LI TY. Effects of bone marrow mesenchymal stem cells on learning and memory functional recovery in neonatal rats with hypoxic-ischemic brain damage. Zhonghua $\mathrm{Er} \mathrm{Ke} \mathrm{Za} Z$ Zhi. 46(2008)648-653 [in Chinese ]

[31] Lee JA, Kim Bi, Jo CH, Choi CW, Kim EK, Kim HS, Yoon KS, Choi JH. Mesenchymal stem-cell transplantation for hypoxic-ischemic brain injury in neonatal rat model. Pediatr Res, 67(2010)42-46

[32] van Velthoven CT, Kavelaars A, van Bel F, Heijnen CJ. Mesenchymal stem cell treatment after neonatal hypoxic-ischemic brain injury improves behavioral outcome and induces neuronal and oligodendrecyte regeneration. Brain Behav Immun. 24(2010)387-393

[33] van Velthoven CT, Kavelaars A, van Bel F, Heijnen CJ. Nasal administration of stem cells: a promising novel route to treat neonatal ischemic brain damage. Pediatr Res. 2010(2010) 419-422

[34] Donega V, van Velthoven CT, Nijboer CH, van Bel F, Kas MJ, Kavelaars A, Heijnen CJ.Intranasal mesenchymal stem cell treatment for neonatal brain damage: long-term cognitive and sensorimotor improvement. PloS One. 8(2013) e51253

[35] Donega V,Nijboer CH, van Tilborg G, Dijkhuizen RM, Kavelaars A, Heijnen CJ. Intranasally administered mesenchymal stem cell promote a regenerative niche for repair of neonatal ischemic brain injury. Exp Neurol. 261(2014)53-64

[36]van Velthoven CT, Braccioli L, Willemen HL, Kavelaars A, Heijnen CJ. Therapeutic potential of genetically modified mesenchymal stem cells after neonatal hypoxic-ischemic brain damage. Mol Ther. 22(2014)645-654

[37] Zhang X, Zhang Q, Li W, Nie D, Chen W, Xu C, Yi X, Shi J, Tian M, Qin G, $\mathrm{Tu}$ W. Therapeutic effect of human umbilical cord mesenchymal stem cells on neonatal rat hypoxic-ischemic encephalopathy. J Neurosci Res. 92(2014)35-45

[38] Zhang DS, Bai XH, Chen DP, Mu DZ, Chen J. Intracerbral transplantation of human umbilical cord-derived mesenchymal stem cell in neonatal rat model of hypoxic-ischemic brain damage:protective effect to injury brain. Zhongguo Dang Dai Er Ke Za Zhi. 16(2014)927-932[ in Chinese ] 
[39] Park WS, Sung SI, Ahn SY, Yoo HS, Sung DK, Im GH, Choi SJ, Chang YS. Hypothermia augments neuroprotective activity of mesenchymal stem cells for neonatal hypoxic-ischemic encephalopathy. PloS One. 27 (2015)10:e0120893

[40] Xia G, Hong X, Chen X, Lan F, Zhang G, Liao L. Intracerebral transplantation of mesenchymal stem cells derived from human umbilical cord blood alleviates hypoxic ischemic brain injury in rat neonates. J Perinat Med. 38 (2010)215-221

[41] Yalvac ME, Rizvanov AA, Kilic E, Sahin F, Mukhamedyarov MA, Islamov RR, Palotás A. Potential role of dental stem cells in the cellular therapy of cerebral ischemia. Curr Pharm Des. 15(2009)3908-3916

[42] Yamagata M, Yamamoto A, Kako E, Kaneko N, Matsubara K, Sakai K, Sawamoto K, Ueda M. Human dental pulp-derived stem cell protect against hypoxic-ischemic brain injury in neonatal mice. Stroke. 44(2013)551-554

[43] Fang CZ, Yang YJ, Wang QH, Yao Y, Zhang XY, He XH. Intraventricular injection of human dental pulp stem cells improves hypoxic-ischemic brain damage in neonatal rats. PloS. 14(2013) e66748

[44] Wang F, Maeda N, Yasuhara T, Kameda M, Tsuru E, Yamashita T, Shen Y,Tsuda M, Date I, Sagara Y. The therapeutic potential of human umbilical cord blood transplantation for neonatal hypoxic-ischemic brain injury and ischemic stroke. Acta Med Okayama. 66(2012)429-434

[45] Pimentel-coelho PM, Magalhães ES, Lopes LM, deAzevedo LC,Santiago MF, Mendez-Otero R. Human cord blood transplantation in a neonatal rat model of hypoxic-ischemic brain damage: functional outcome related to neuroprotection in the striatum. Stem Cell Dev. 19(2010)351-358

[46] Wang X, Zhao Y, Wang X. Umbilical cord blood cells regulate the differentiation of endogenous neural stem cells in hypoxic ischemic neonatal rat via the hedgehog signaling pathway. Brain Res. 1560(2014)18-26

[47] Huang HZ, Wen XH, Liu H, Huang JH, Liu SQ, Ren WH, Fang WX, Qian YF, Hou WZ, Yan MJ, Yao YH, Li WZ, Li QJ. Human umbilical cord blood mononuclear cell transplantation promotes long-term neurobehavioral functional development of newborn SD rats with hypoxic ischemic brain injury. Zhonghua Er Ke Za Zhi. 51(2013)460-466 [in Chinese ]

[48] Ghaffanripour HA, Jalali M, Nikravesh MR, SeghatoleslamM, Sanchooli J. Neuronal cell reconstruction with umbilical cord blood cells in the brain hypoxia-ischemia. Iran Biomed J. 19(2015)29-34

[49] Greggio S, de Paula S, Azevedo PN, Venturin GT, Dacosta JC. Intra-arterial transplantation of human umbilical cord blood mononuclear cells in neonatal hypoxic-ischemic rats. Life Sci. 96(2014)33-39

[50] de paula S, Greggio S, Marinowic DR, Machado DC, DaCosta JC. The dose-response effect of acute intravenous transplantation of human umbilical cord blood cells on brain damage and spatial memory deficits in neonatal hypoxia-ischemia. Neuroscience.210 (2012)431-441

[51] Yasuhara T, Hara K, Maki M, Xu L, Yu G, Ali MM, Masuda T, Yu SJ, Bae EK, Hayashi T, Matsukawa N, Kaneko Y, Kuzmin-Nichols N, Ellovitch S, Cruz EL, 
Klasko SK, Sanberg CD, Sanberg PR, Borlongan CV. Mannitol facilitates neurotrophic factor up-regulation and behavioural recovery in neonatal hypoxic-ischaemic rats with human umbilical cord blood grafts. J Cell Mol Med. 14(2010) 914-921

[52] Chaffari HA, Jalali M, Nikravesh MR, Seghatoleslam M, Sanchooli J. Neuronal cell reconstruction with umbilical cord blood cell in the brain hypoxia-ischemia. Iran Biomed J. 19(2015)29-34 